\title{
Excellent Response and Recovery Time of Photo-Detectors Based on Nc-Si:H Films Grown by Using Hot Wire Method
}

\author{
Vijaya Jadkar ${ }^{1}$, Amit Pawbake ${ }^{1}$, Ashok Jadhavar', Ravindra Waykar ${ }^{1}$, Subhash Pandharkar ${ }^{1}$, Ajinkya Bhorde ${ }^{1}$, Rahul Aher ${ }^{1}$, Shruthi Nair ${ }^{1}$, Bharat $^{2}$ \\ Gabhale $^{1}$, Ashish Waghmare ${ }^{1}$, Dhirsing Naik ${ }^{1}$, Priti Vairale ${ }^{1}$, Suresh Gosavi ${ }^{2}$ and Sandesh Jadkar ${ }^{2 *}$
}

In present study, we have synthesized highly crystalline hydrogenated nanocrystalline silicon ( $n c-\mathrm{Si}: \mathrm{H})$ thin films by hot wire method. The obtained thin films were characterized by using low angle-XRD, Raman spectroscopy, non-contact atomic force microscopy (NC-AFM) and UV-Visible spectroscopy. The low angle-XRD analysis revealed that the obtained nc-Si:H thin films are polycrystalline and have preferred orientation along (111) direction. The formation of nc-Si:H films was further confirmed by Raman spectroscopy analysis. The UV-Visible spectroscopy analysis showed that the synthesized films had a sharp absorption edge in the visible region and had a direct band gap of $\sim 1$. 94 eV. Finally, nc-Si:H based photo-detector has been prepared at optimized process parameters which showed an excellent response time (1.79 s) and recovery time $(1.71 \mathrm{~s})$ along with responsivity $\left(\sim 9.8 \times 10^{-8} \mathrm{~A} / \mathrm{W}\right)$, detectivity $\left(\sim 5.5 \times 10^{4} \mathrm{Jones}\right)$ and quantum efficiency $\left(\sim 27.37 \times 10^{-6} \%\right)$. The obtained results demonstrate a significant step towards nc-Si:H based photo-detector for broad band photo-detection applications.

Keywords: Hot wire method; Nc-Si:H; Low angle XRD; Raman spectroscopy; Photo-detector

Received 10 April 2019, Accepted 5 August 2019

DOI: $10.30919 / \mathrm{esmm} 5 \mathrm{f} 236$

\section{Introduction}

Photo-detectors or photo-sensors are essential in opto-electronic devices for a variety of applications, ranging from biomedicine to optical storage. ${ }^{1,2}$ Semiconductor materials from various groups such as group IV elements ( $\mathrm{Si}, \mathrm{Ge})$, group III-V compounds (GaN, GaAs, InP), and group II-VI compounds ( $\mathrm{ZnS}, \mathrm{ZnO}, \mathrm{CdS}, \mathrm{CdSe}$ ) are most commonly used in photo-detectors. Most of them require a relatively long response time and recovery time and thus limits their practical applications.

The crystalline silicon (c-Si) is the most commonly used in nanoelectronics technology due to its enormous availability in the earth crust, ${ }^{3}$ high mobility and high temperature stability etc. ${ }^{4}$ Furthermore, cSi has superior intrinsic concentration $\left(10^{10} \mathrm{~cm}^{-3}\right)$ that leads to small leakage current, the most important aspect in nano-electronics device fabrications ${ }^{5}$ and maximum solid solubility of dopants $\left(\sim 10^{21} \mathrm{~cm}^{-3}\right)$ so that one can change the carrier type and concentration in a very large range for optimum operation of the devices. ${ }^{6}$ However, it fails for device applications in opto-electronics due to its indirect band gap. The nanoscale $\mathrm{Si}$ (nc-Si) materials with size dependent properties are potential candidates for photonic devices. ${ }^{7}$ The material has been successfully employed in solar cells, ${ }^{8}$ transistors, ${ }^{9}$ sensors, ${ }^{10}$ field emission, ${ }^{11}$ water splitting, ${ }^{12}$ super-capacitors, ${ }^{13}$ waveguides, ${ }^{14}$ coatings, ${ }^{15}$ photo-detection ${ }^{16}$ etc. There are several methods/approaches reported in literature for synthesis of device quality nc-Si thin films such as pulsed laser

${ }^{1}$ School of Energy Studies, Savitribai Phule Pune University, Pune, 411 007, India

${ }^{2}$ Department of Physics, Savitribai Phule Pune University, Pune 411 007, India

*E-mail: sandesh@physics.unipune.ac.in deposition (PLD), ${ }^{17}$ atomic layer deposition (ALD) ${ }^{18}$ hot wire chemical vapour deposition (HW-CVD) or simply hot wire method, ${ }^{19}$ plasma enhanced chemical vapour deposition (PE-CVD), ${ }^{20}$ sputtering $^{21}$ etc. The inherent indirect band gap of c-Si $(\sim 1.1 \mathrm{eV})$ limits its ability to convert light below its band edge into photocurrent. The photocurrent can be generated only when the photon energy is slightly higher than the Schottky barrier height. In addition, the undesirable near infrared (NIR) photo-response due to small band gap causes additional optical noise but when coupled with optical filter technique increase structural complexity and cost dramatically. ${ }^{22}$

Knight et al..$^{23}$ proposed a distinguished concept of using an active antenna for photo-detection well below the band edge of the semiconductor material. Using filtered cathodic vacuum arc (FCVA) technique Tripathi et al. ${ }^{24}$ developed phosphorous doped hydrogenated amorphous silicon carbide (P doped a-SiC:H) thin film photo detectors at room temperature having fast response and recovery time. Later, using the same technique Kesarwani et al. ${ }^{25}$ synthesized phosphorus doped amorphous/nanocrystalline silicon thin film photo detectors in the presence of hydrogen gas having good fast response and recovery time. Recently, Tripathi and others ${ }^{26}$ reported nc-Si:H based photo-detector having fast response time (4.92 s) and recovery time (4.06 s) using filtered cathodic vacuum arc technique at room temperature. Due to quantum confinement the nano-sized Si based photodetectors are not only detect photons below its band edge but also provide a great potential for on-chip silicon photonics. With this motivation an attempt has been made to prepare device quality nc-Si:H films and to fabricate photo-detector device using it by hot wire method. The photo-detector shows excellent response time (1.79 s) and recovery time (1.71 s) along with responsivity $\left(9.8 \times 10^{-8} \mathrm{~A} / \mathrm{W}\right)$, detectivity ( $5.5 \times 10^{4}$ Jones $)$ and quantum efficiency $\left(27.37 \times 10^{-6} \%\right)$. The obtained results open up a new 
opportunity for industrial application of broad band photo-detector based on nc-Si:H thin films.

\section{Experimental}

\subsection{Synthesis of nc-Si:H thin films}

Intrinsic nc-Si:H films were deposited on Corning \#7059 glass in a locally fabricated hot wire system, details of which have been described elsewhere. ${ }^{27}$ Films were prepared by using pure silane $\left(\mathrm{SiH}_{4}\right)$ as $\mathrm{Si}$ source gas and hydrogen $\left(\mathrm{H}_{2}\right)$ as dilution gas. The flow rate of $\mathrm{SiH}_{4}$ and $\mathrm{H}_{2}$ are kept constant at $2.5 \mathrm{sccm}$ and $50 \mathrm{sccm}$ respectively while filament temperature was kept constant at $1900{ }^{\circ} \mathrm{C}$. The pressure during deposition was kept constant at 0.0667 mbar using manual throttle valve. The substrate temperature was held constant $\left(350{ }^{\circ} \mathrm{C}\right)$ using a thermocouple and temperature controller and the filament-to-substrate distance $\left(\mathrm{d}_{\mathrm{sf}}\right)$ was fixed at $5 \mathrm{~cm}$. The substrates were cleaned with double distilled water and loaded to the substrate holder. Then the deposition chamber was evacuated to the base pressure less than $1.3332 \times 10^{-6}$ mbar. Prior to each deposition, the substrate holder and deposition chamber were baked for two hours at $100{ }^{\circ} \mathrm{C}$ to remove any water vapours absorbed on the substrates and to reduce the oxygen contamination in the film. After that, the substrate temperature was brought to desired value by appropriately setting the inbuilt thermocouple and temperature controller. The deposition was carried out for desired time and films were allowed to cool to room temperature in vacuum.

\subsection{Characterization techniques}

The transmittance and reflectance spectra of nc-Si:H films were measured using a JASCO, V-670 UV-Visible spectrophotometer in the range 300-1800 $\mathrm{nm}$. The optical band gap of was deduced using the method followed by Tauc. Raman spectra were recorded with Renishaw microscope in the range $100-700 \mathrm{~cm}^{-1}$. The spectrometer has backscattering geometry for detection of Raman spectrum with the resolution of $1 \mathrm{~cm}^{-1}$. The excitation source was $632.8 \mathrm{~nm}$ line of $\mathrm{He}-\mathrm{Ne}$ laser. The power of the Raman laser was kept to less than $5 \times 10^{-3} \mathrm{~W}$ to avoid laser induced crystallization in the films. Low angle x-ray diffraction pattern were obtained by x-ray diffractometer (Bruker D8 Advance, Germany) using $\mathrm{Cu} \mathrm{K} \mathrm{K}_{\alpha}$ line $(\lambda=1.54056 \AA)$. The patterns were taken at a grazing angle of $1^{0}$. The average crystallite size was estimated using the classical Scherrer's formula. The surface morphology of the films has been investigated using non-contact atomic force microscopy (NC-AFM) (Bruker MultiMode $8 \mathrm{HR}$, Germany). Thickness of films was determined by profilometer (KLA Tencor, P$16+$ ) and was further confirmed by UV-Visible spectroscopy using the method proposed by Swanepoel. ${ }^{28}$

\section{Results and Discussion}

The process parameters play a crucial role in determining the film properties in hot wire method. These parameters affect the film properties in different ways and in order to obtain desired film properties an optimum set of the parameters is to be selected. Although a particular set of optimized process parameters designed for a particular deposition system do not necessarily apply universally, but only serve as a good guideline.

Our group has analysed the influence of various hot wire process parameters on film properties to obtain device quality nc-Si:H films. Therefore, in this article, first we will be discussing the formation of ncSi:H films at optimized process parameters (see Table 1) of our hot wire reactor. Later, we present the sensor properties of nc-Si:H based photodetector.

\subsection{Low angle XRD analysis}

In order to confirm the formation of nc-Si:H film by hot wire method, low angle-XRD and Raman spectroscopy have been used. Fig. 1 displays the low angle-XRD pattern of $\mathrm{Si}: \mathrm{H}$ thin film deposited under the optimum deposition parameters by using hot wire method. As seen from the figure, low angle-XRD pattern show three distinct peaks at $2 \theta$ $28.4^{\circ}, 46.9^{\circ}$ and $55.8^{\circ}$ corresponding to (111), (220) and (311) crystal orientations of nc-Si:H, respectively. These results are consistent with the results reported in the literature ${ }^{29,30}$ and support to the formation of nc-Si:H films by hot wire method. The dominant peak is (111), indicating that the crystallites in the film have preferential orientation in (111) direction.

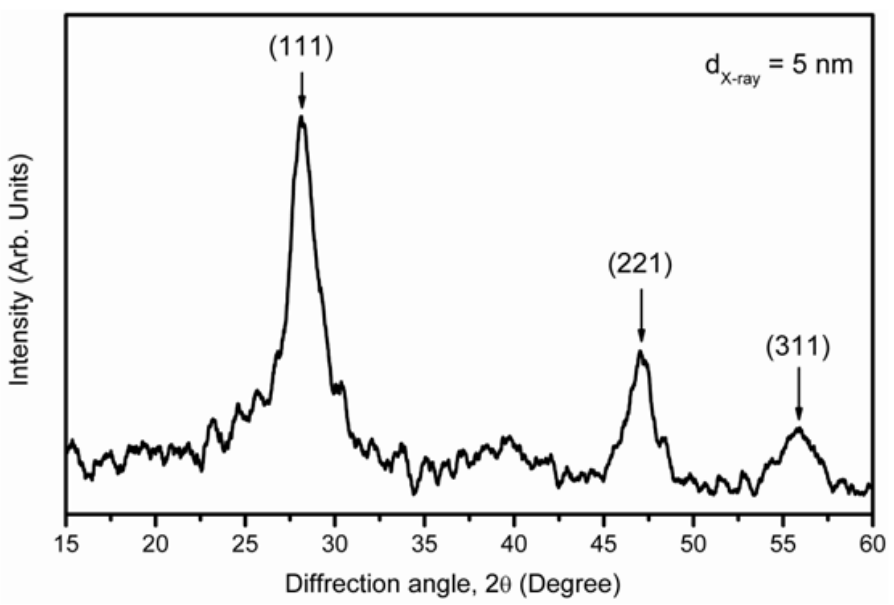

Fig. 1 Low angle-XRD pattern of nc-Si:H deposited using hot wire method at optimized process parameters.

Table 1 Optimized process parameters to obtain device quality nc-Si:H films.

\begin{tabular}{lc}
\hline Process Parameter & Process Value \\
\hline Filament Temperature $\left(\mathrm{T}_{\mathrm{fil}}\right)$ & $1900{ }^{\circ} \mathrm{C}$ \\
Deposition Pressure $\left(\mathrm{P}_{\mathrm{dep}}\right)$ & $0.0667 \mathrm{mbar}$ \\
Substrate Temperature $\left(\mathrm{T}_{\mathrm{sub})}\right.$ & $350^{\circ} \mathrm{C}$ \\
Filament to Substrate Distance $\left(\mathrm{d}_{\mathrm{s}-\mathrm{f}}\right)$ & $5 \mathrm{~cm}$ \\
Deposition time $(\mathrm{t})$ & $20 \mathrm{Min}$ \\
\hline
\end{tabular}


The average crystallite size $\left(\mathrm{d}_{\mathrm{x} \text {-ay }}\right)$ of $\mathrm{Si}$ crystallites was deduced using Debye-Scherrer's formula, ${ }^{31}$

$$
\mathrm{d}_{\mathrm{x}-\mathrm{ay}}=\frac{0.9 \lambda}{\beta \cos \theta_{\mathrm{B}}}
$$

where, $\lambda$ is the wavelength of diffracted radiation, $\theta_{\mathrm{B}}$ is the Bragg angle and $\beta$ is the line width (FWHM) in radians. The calculated value of crystallite size was found $\sim 5 \mathrm{~nm}$. These results are in consistent with the nc-Si:H films prepared by hot wire method at different filament temperatures by Gogoi et al.

\subsection{Raman spectroscopy analysis}

Raman spectroscopy is a very powerful and non-destructive characterization method used to investigate the structure of materials because it gives a fast and simple way to determine the phase of the material, whether it is amorphous, crystalline or nanocrystalline. Thus, to confirm the formation of nc-Si:H, Raman spectroscopy was used. Fig. 2 show Raman spectrum of $\mathrm{Si}: \mathrm{H}$ film deposited by hot wire method at optimized process parameters. The Raman spectra show a satellite shoulder centred $\sim 514.17 \mathrm{~cm}^{-1}$, associated with the Transverse Optic (TO) phonon peak originating from nanocrystalline phase. ${ }^{33}$

To estimate the volume fraction of crystallites $\left(X_{\text {Raman }}\right)$ and crystallite size $\left(\mathrm{d}_{\text {Raman }}\right)$, the Raman was de-convoluted into three peaks (Two Gaussian and One Lorentzian peak) with a quadratic base line using Levenberg-Marquardt method, ${ }^{34}$ a crystalline peak $\left(\sim 520 \mathrm{~cm}^{-1}\right)$, an amorphous peak $\left(\sim 480 \mathrm{~cm}^{-1}\right)$ and an intermediate peak, $\left(\sim 510 \mathrm{~cm}^{-1}\right)$. The typical de-convoluted Raman spectrum is shown in the inset of the Fig. 1(c). The crystalline volume fraction $\left(X_{\text {Raman }}\right)$ is then calculated by using the equation,

$$
X_{\text {raman }}=\frac{I_{c}+I_{m}}{I_{c}+I_{m}+\sigma I_{s}}
$$

where $\sigma$ is the ratio of Raman cross-section for the amorphous phase to the crystalline phase and is taken as $1.0,{ }^{36} \mathrm{I}_{\mathrm{c}}$ is the integrated intensity of the crystalline peak centered around $520 \mathrm{~cm}^{-1}, \mathrm{I}_{\mathrm{m}}$ is the integrated intensity of the intermediate phase or grain boundaries centered between $500-510 \mathrm{~cm}^{-1}$ and $\mathrm{I}_{\mathrm{a}}$ is the integrated intensity of the broad amorphous peak centered at $480 \mathrm{~cm}^{-1}$.

The crystallite size $\left(\mathrm{d}_{\text {Raman }}\right)$ is then given by, ${ }^{37}$

$$
\mathrm{d}_{\text {Raman }}=2 \pi \sqrt{\frac{\beta}{\Delta \omega}}
$$

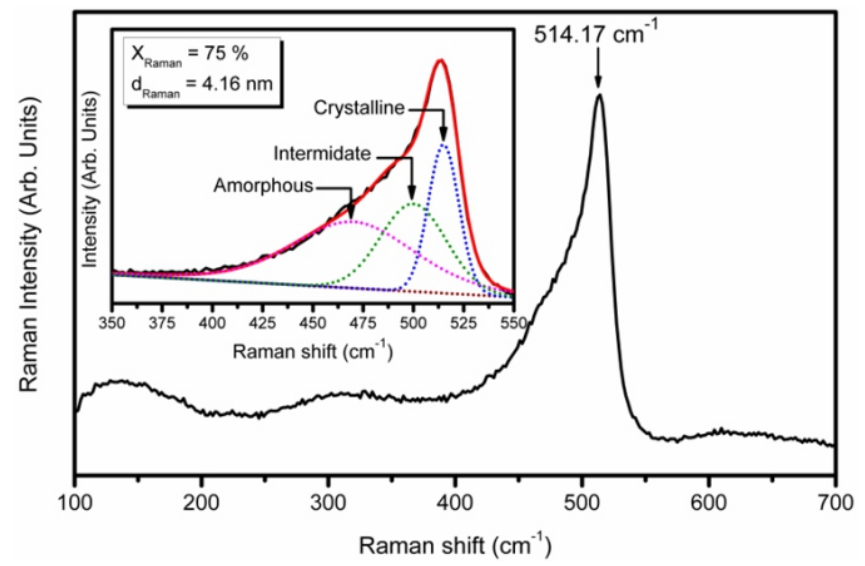

Fig. 2 Room temperature Raman spectrum of nc-Si:H deposited using hot wire method at optimized process parameters. The inset shows deconvoluted Raman spectrum for the estimation of volume fraction of crystallites and crystallite size. where $\Delta \omega$ is the peak shift compared to c-Si peak located $\sim 520 \mathrm{~cm}^{-1}$ and $\beta=2.0 \mathrm{~cm}^{-1} \mathrm{~nm}^{238}$. The volume faction of crystallite, $X_{\text {Raman }}$ and crystallite size, $\mathrm{d}_{\text {Raman }}$ for the synthesized nc-Si:H film was found $75 \%$ and $4.16 \mathrm{~nm}$ respectively. Similar results were obtained by Chong and his group $^{39}$ for nc-Si:H films deposited at different substrate temperatures by hot wire CVD. The results obtained in the present study are consistent with low angle XRD analysis which further confirm the formation of nc-Si:H film by hot wire method.

\subsection{UV-Visible spectroscopy analysis}

Fig. 3 shows the optical properties of nc-Si:H prepared using hot wire method at optimized process parameters. Fig. 3(a) display the transmittance spectra of nc-Si:H prepared using hot wire method in the range $300-1800 \mathrm{~nm}$. As seen from the transmission spectra a sharp absorption edge has been observed in visible region, indicating good degree of crystallinity and low defect density near the band edge. Furthermore, the nc-Si:H has maximum transmission in IR region. The presence of interferences fringes in film transmittance spectra indicates that the film has smooth surface morphology. Atomic force microscopy analysis further supports this (discussed later).

The absorption coefficient $(\alpha)$ was estimated from transmission (T) and reflection (R) spectra in the wavelength range of 200-900 nm. The optical absorption coefficient $(\alpha)$ is calculated for each wavelength using the relation.

$$
\alpha=\frac{1}{\mathrm{~d}} \operatorname{In}\left(\frac{\mathrm{T}}{1-\mathrm{R}}\right)
$$
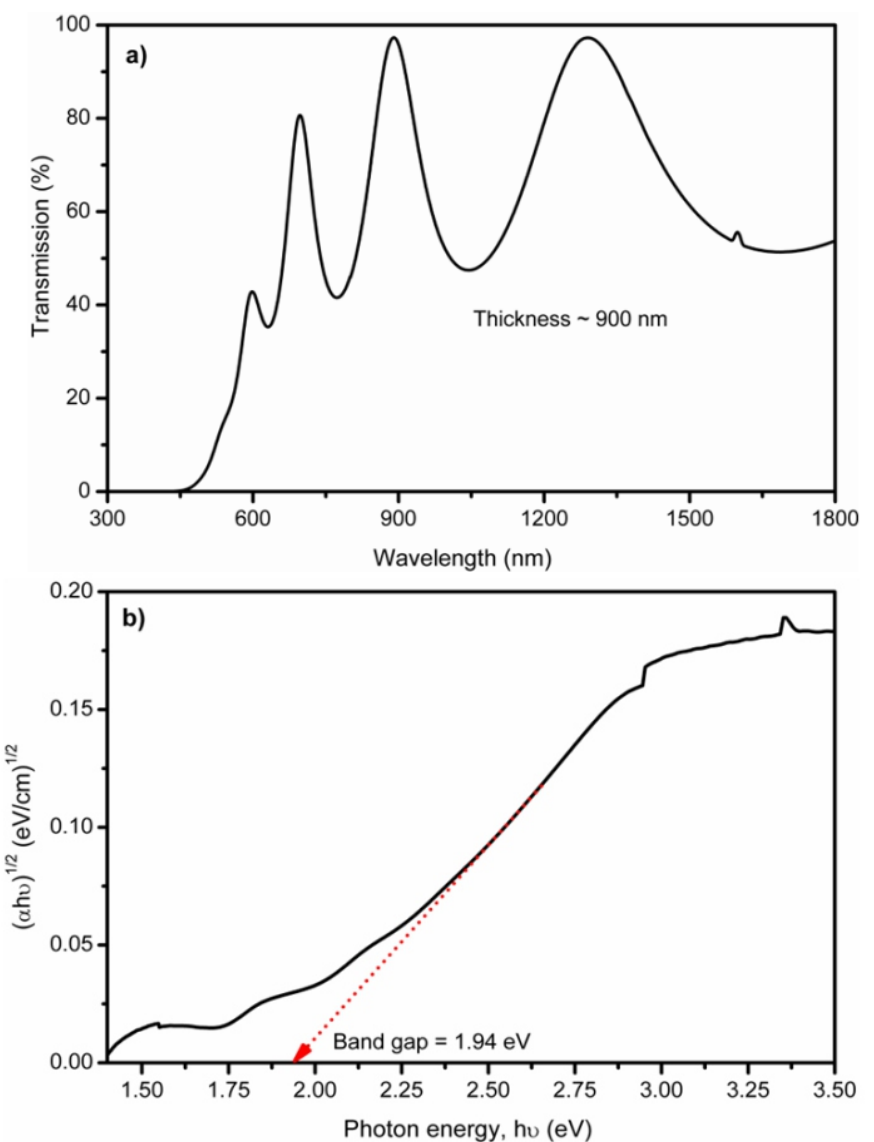

Fig. 3 a) UV-Visible transmission spectra spectrum of nc-Si:H deposited using hot wire method at optimized process parameters and b) Plot of $(\alpha h v)^{1 / 2}$ versus photon energy (hv) (Tauc) to calculate the optical band gap. 
where, $d$ is the thickness of film. The optical band gap $\left(\mathrm{E}_{\text {opt }}\right)$ of the film was then calculated from the dependence of the absorption coefficient $(\alpha)$ on the photon energy (hv) taking into account for the semiconductor. For direct allowed transition, absorption coefficient $(\alpha)$ and band gap can be expressed as, ${ }^{40}$

$$
(\alpha \mathrm{h} v)^{n}=\mathrm{B}\left(\mathrm{h} v-\mathrm{E}_{\mathrm{g}}\right)
$$

where, $\mathrm{B}$ is an energy independent constant and $\mathrm{n}$ is a constant which determines type of optical transition $(n=1 / 2$ for direct transition and $n$ $=2$ for indirect transition). ${ }^{41}$ To determine the band gap, $(\alpha h v)^{1 / 2}$ is plotted against energy E $(=h v)$ (Tauc plot). A straight line fitted through the data points. A straight line fitting program was developed to fit the data in a straight line. Then the line is extrapolated and the intercept of the extrapolated line on the energy axis gives the band gap. The inset of Fig. 3(b) depicts typical Tauc plot used to estimate the optical band gap $\left(\mathrm{E}_{\text {Tauc }}\right)$ of nc-Si:H. The calculated value of optical band gap of nc-Si:H film was found $\sim 1.94 \mathrm{eV}$. The value of optical band gap matches with recently reported values for $\mathrm{nc}-\mathrm{Si}: \mathrm{H}$ films measured by spectroscopic ellipsometry (SE). ${ }^{42}$

\subsection{Atomic force microscopy (AFM) analysis}

To study the morphology of nc-Si:H film, atomic force microscopy (AFM) measurements were performed in non-contact mode on the films deposited on corning glass at optimized process parameters. Fig. 4 shows the surface morphology of the nc-Si:H on $2 \mu \mathrm{m} \times 2 \mu \mathrm{m}$ area of the films.

It is clearly observed from the AFM image that the film is very uniform throughout the sample. The film consists of well resolved, large number of nearly spherical and uniform nano-crystallites each having an individual identity with its size in the range of $\sim 20-25 \mathrm{~nm}$. The root mean square (RMS) surface roughness of nc-Si:H was estimated from AFM image using Scanning Probe Image Processor (SPIP) software. The RMS surface roughness values of the films obtained from AFM analysis was found $39 \mathrm{~nm}$. Gope et al. ${ }^{43}$ also reported similar average crystalline size $(\sim 35.5 \mathrm{~nm})$ and RMS surface roughness $(\sim 11.32 \mathrm{~nm})$ for nc-Si:H films deposited at low process pressure (1.3332 mbar) using very high frequency plasma enhanced chemical vapor deposition (VHF PECVD) process.

\section{5: Photo-detector properties}

The photo-detector is fabricated by directly depositing nc-Si:H on corning glass using the optimized process parameters listed in Table 1. The thickness of nc-Si:H layer is $~ 900 \mathrm{~nm}$. Using metal mask silver $(\mathrm{Ag})$ source and drain electrodes were deposited on nc-Si:H by vacuum evaporation technique. The schematic of nc-Si:H photo-detector device fabricated using optimized process parameters of hot wire method is shown in Fig. 5.

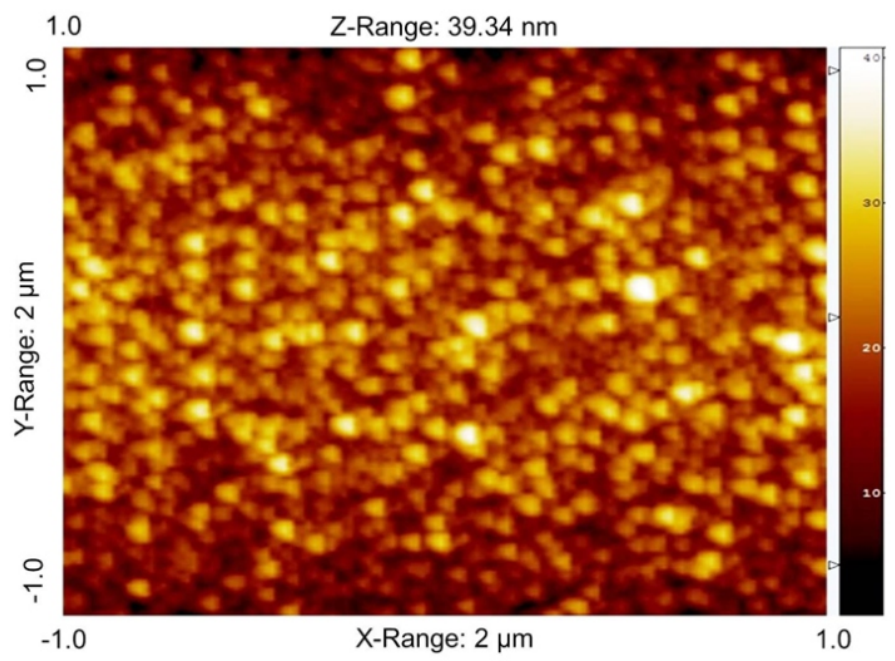

Fig. 4 NC-AFM image of nc-Si:H film deposited by hot wire method at optimized process parameters.

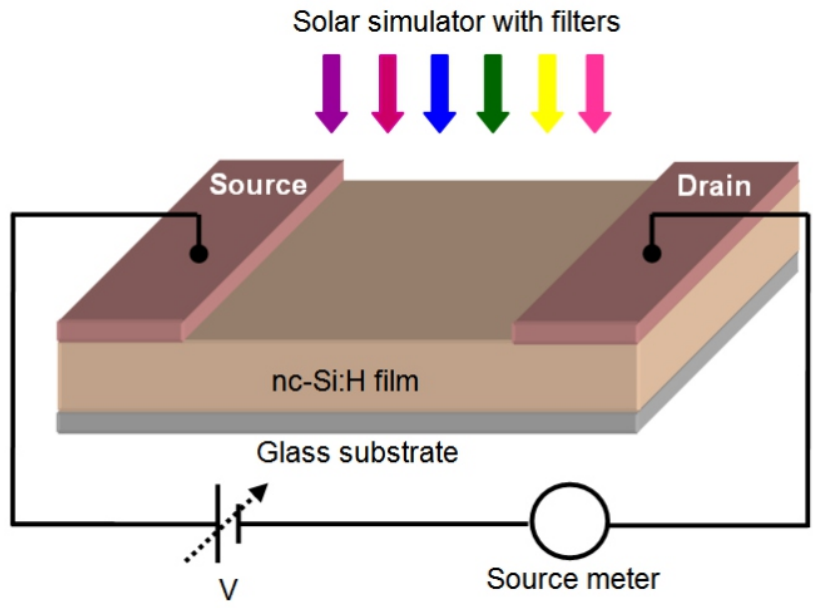

Fig. 5 Schematic of nc-Si:H photo-detector fabricated using hot wire method at optimized process parameters. 
The performance of nc-Si:H photo-detector was evaluated using Keithley 2612 source meter connected to PC through GPIB 488 A interface. For white light illumination PEC-L01 portable solar simulator was used which provide wide range of spectrum from Ultraviolet (UV) to near infrared (IR) region. In the present study, white light having intensity $100 \mathrm{~mW} / \mathrm{cm}^{2}$ have been employed for the photo-detector property measurements. The VIBGYOR filters were used to investigate wavelength dependant photo-detection investigation of nc-Si:H photodetector.

In many reviews and articles, the working principle of the photodetector is explained in detail. ${ }^{446}$ Basically, it is a sensor that is capable of converting incident light into electrical signal. Due to the incident light energy, electrons at the semiconductor surface get excited to new energetic conductive levels by leaving a hole behind. This photon excitation leads to generation of exciton (electron-hole pair, EHP). After the application of the electric field, the electron and hole drifts inside the crystal lattice and generate photocurrent. Sensitivity, response and decay time measurements are very important parameters in order to characterize the performance of the photo-detector.

Fig. 6 display current-voltage (I-V) characteristics of nc-Si:H photo-detector under dark and illumination of different light (VIBGYOR) filters in the range of $-1 \mathrm{~V}$ to $1 \mathrm{~V}$.

It is clear from the graph that the resistance of nc-Si:H decreases after illumination of light. The photocurrent strongly depends on electron-hole separation and thermal mechanisms. ${ }^{47}$ On absorption of photons the photo-detector material, nc-Si:H create extra charge carriers, electrons and holes which drift in opposite directions towards sourcedrain metal leads. This reduces the electrical resistance and results in a net increase in the photo-current. These results confirms the semiconducting behaviour of nc-Si:H by hot wire method.

The time dependent current response of nc-Si:H photo-detector for repeated cycles is illustrated in Fig. 7. Fig. 8 shows a single-cycle I-t curve for measuring the response time $\left(\tau_{\text {rise }}\right)$ and recovery time $\left(\tau_{\text {rdecay }}\right)$ of nc-Si:H photo-detector using white light. Response time is defined as the time required for a photo-detector reaching $90 \%$ of its maximum photocurrent value from its dark current value. Similarly, decay time is defined as the time required for photo-detector reaching $10 \%$ of maximum photocurrent response. ${ }^{48}$ The response and recovery time for nc-Si:H photo-detector under white light were found to be $\sim 1.79 \mathrm{~s}$ and $\sim 1.71$ s respectively.

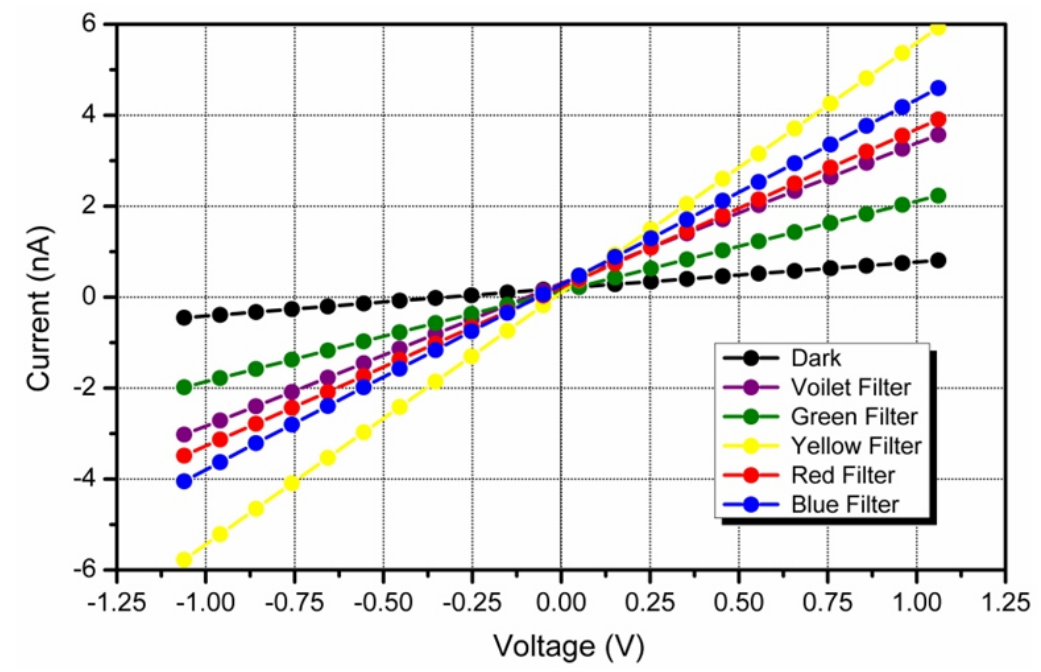

Fig. $6 \mathrm{I}-\mathrm{V}$ characteristics of nc-Si:H photo-detector under dark and under VIBGYOR filters at applied voltage of $1 \mathrm{~V}$.

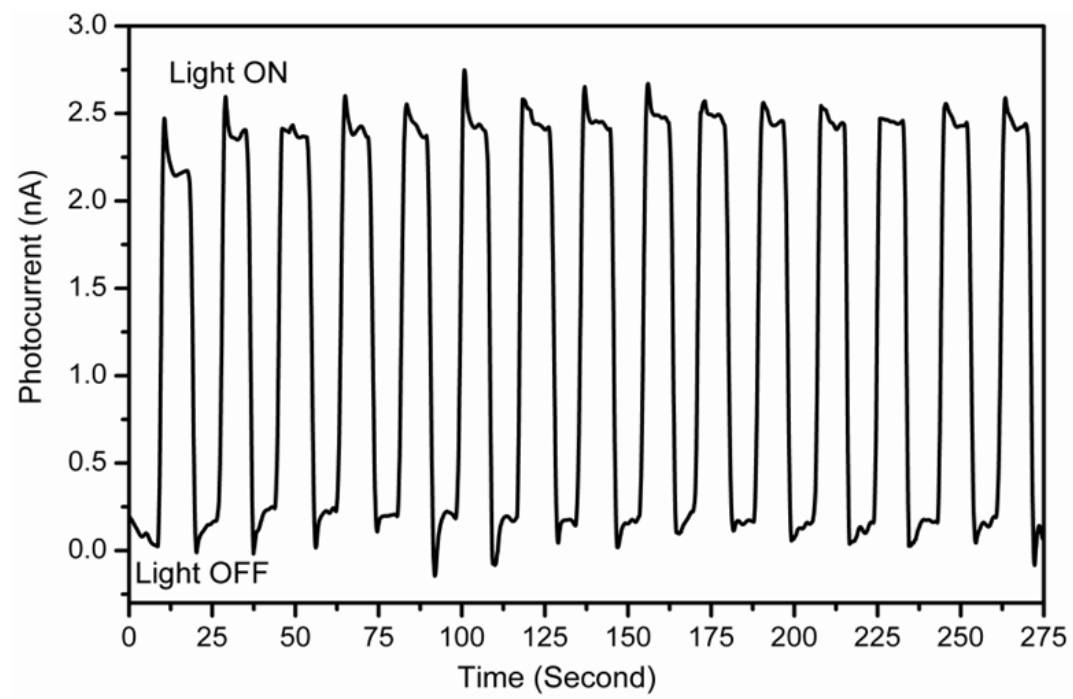

Fig. 7 Current-time (I-t) characteristics of nc-Si:H photo-detector upon illumination of white light for repeated cycles. 
The obtained response and recovery time for nc-Si:H photodetector are compared with some other photo-detector materials and corresponding fabrication methods are listed in Table 2.

As evident from Table 2 that the nc-Si:H based photo-detector has excellent response and recovery time compared to other photo-detector materials.

The photo-sensitivity of photo-detector ( $\mathrm{S} \%$ ) is defined as the ratio between the difference in photo current $\left(\mathrm{I}_{\text {photo }}\right)$ and dark current $\left(\mathrm{I}_{\text {dark }}\right)$ values to the dark current, ${ }^{48}$

$$
\text { Sensitity }(\mathrm{S} \%)=\frac{\mathrm{I}_{\text {photo }}-\mathrm{I}_{\text {Dark }}}{\mathrm{I}_{\text {dark }}} \times 100 \%
$$

Fig. 9 shows sensitivity of photo-detector obtained at different colours of the radiation spectra.

As seen from the figure for hot wire deposited nc-Si:H photodetector has the highest sensitivity ( $24 \%$ ) for the white light and lowest for the green light ( $12 \%$ ).

Photo-responsivity, photo-detectivity and external quantum efficiency measurements are very important parameters in order to describe the performance of photo-detector. The photo-responsivity $\left(\mathrm{R}_{\lambda}\right)$ refers to the photo-excited current generated per unit power of incident light on the effective area of the photo-detector and is given as, ${ }^{53}$

$$
\mathrm{R}_{\lambda}=\frac{\Delta \mathrm{I}}{\omega \times \mathrm{A}}
$$

where $\Delta \mathrm{I}=\left(\mathrm{I}_{\text {photo }}-\mathrm{I}_{\text {dark }}\right)$ is the effective change in the emission current upon visible photon irradiation, $\omega$ is the intensity of incident photons $\left(100 \mathrm{~mW} / \mathrm{cm}^{2}\right)$ and $\mathrm{A}$ is area of photo-detector $\left(0.25 \mathrm{~cm}^{2}\right)$. The photoresponsivity of the nc-Si:H for visible illumination is found to be $9.8 \times 10^{-8} \mathrm{~A} / \mathrm{W}$.

To evaluate the efficiency of the electron transport and carrier collection we have estimated the probable quantum efficiency (QE) of nc-Si:H photo-detector using the equation, ${ }^{54}$

$$
\mathrm{QE}(\%)=\frac{\mathrm{h} \times \mathrm{c} \times \mathrm{R}_{\lambda}}{\mathrm{e} \times \lambda} \times 100 \%
$$

where $\mathrm{h}$ is a Plank's constant, $\mathrm{c}$ is a velocity of light; e is charge of the electron and $\lambda$ is a wavelength of the incident radiations The quantum efficiency of nc-Si:H photo-detector was found $27.37 \times 10^{-6} \%$.

For photo-detectors one of the essential parameter is detectivity $\left(D^{*}\right)$, which gives a measure of quality of device. It helps in comparing distinct devices with different area and geometries. It is measured in the unit of Jones and is given by, ${ }^{55}$

$$
\mathrm{D}^{*}=\frac{\mathrm{R}_{\lambda}}{\left(2 \mathrm{e} \times \mathrm{J}_{\text {Dark }}\right)^{1 / 2}}
$$

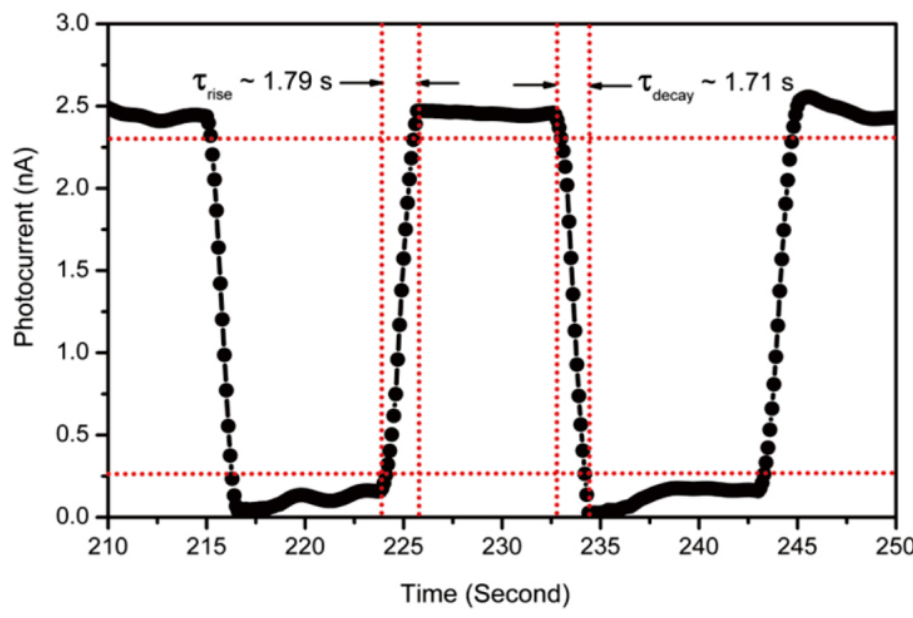

Fig. 8 Single-cycle I-t curve for measurement of response and recovery time of nc-Si:H photo-detector.

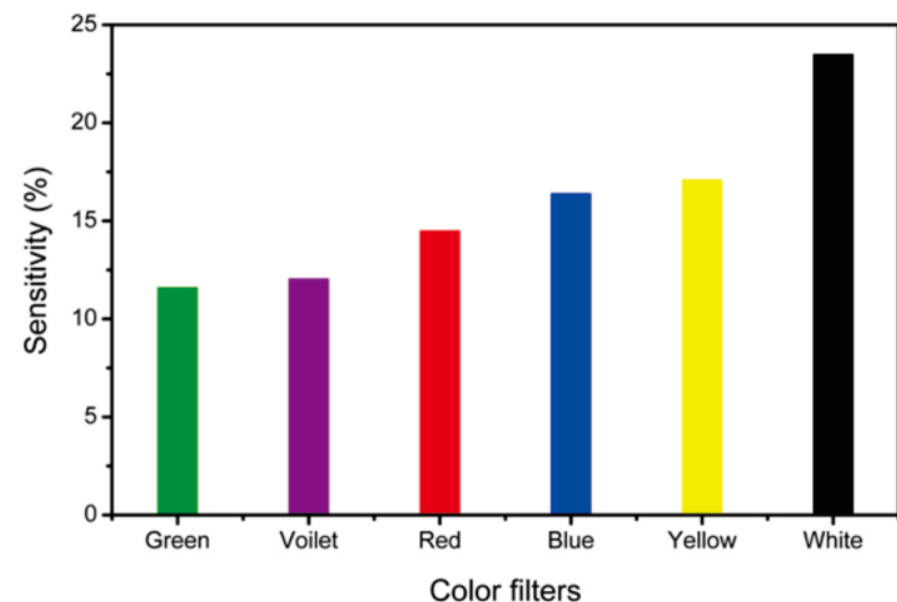

Fig. 9 Sensitivity of nc-Si:H photo-detector obtained under the illumination of different colours.

Table 2 Response and recovery time of recent photo-detector materials and their fabrication method.

\begin{tabular}{lllll}
\hline Material & Synthesis method & Response time & Recovery time & Reference \\
\hline & - & $20 \mathrm{~s}$ & $10.97 \mathrm{~s}$ & {$[49]$} \\
$\mathrm{MoS}_{2}$ & Chemical vapour deposition & $1.79 \mathrm{~s}$ & $1.23 \mathrm{~s}$ & {$[50]$} \\
& & & & {$[51]$} \\
$\mathrm{WS}_{2}$ & HLD & $4.1 \mathrm{~s}$ & $4.4 \mathrm{~s}$ & {$[27]$} \\
& Chet wire method & $51 \pm 5 \mathrm{~s}$ & $88 \pm 6 \mathrm{~s}$ & {$[52]$} \\
$\mathrm{SnSe}$ & Hot wire method & $8.2 \mathrm{~s}$ & $5.3 \mathrm{~s}$ & Present \\
$\mathrm{nc}-\mathrm{Si}: \mathrm{H}$ & & $\sim 1.79 \mathrm{~s}$ & $\sim 1.71 \mathrm{~s}$ & \\
\hline
\end{tabular}


where, $\mathrm{J}_{\text {Dark }}$ is the dark current density. We observed the value of detectivity ( $\mathrm{D}^{*} \sim 5.5 \times 10^{4}$ Jones) for $\mathrm{nc}-\mathrm{Si}: \mathrm{H}$ photo-detector. Noise from the dark current, Johnson noise, generation-recombination noise, and thermal fluctuation (flicker noise) limits the detectivity. ${ }^{56}$

\section{Conclusion}

We have synthesized hydrogenated nanocrystalline silicon (nc-Si:H) thin films using hot wire method. Formation of nc-Si:H have been confirmed by low angle-XRD and Raman spectroscopy analysis. The low angleXRD and Raman spectroscopy analysis revealed that nc-Si:H thin films are highly crystalline and crystallites have preferred orientation along (111) direction. Formation of nc-Si:H thin films were also confirmed by non-contact atomic force microscopy which formation of well resolved, large number of nearly spherical and uniform Si nano-crystallites having average size in the range of $\sim 20-25 \mathrm{~nm}$. The UV-Visible spectroscopy analysis showed that the synthesized films have sharp absorption edge in visible region and has direct band gap of $1.94 \mathrm{eV}$. The photodetector fabricated using nc-Si:H shows excellent response time (1.79 s) and recovery time $(1.71 \mathrm{~s})$ along with responsivity $\left(\sim 9.8 \times 10^{-8} \mathrm{~A} / \mathrm{W}\right)$, detectivity $\left(\sim 5.5 \times 10^{4}\right.$ Jones) and quantum efficiency $\left(\sim 27.37 \times 10^{-6} \%\right)$. The obtained results reveal potential applications of hot wire deposited nc-Si:H as a photo-detector.

\section{Acknowledgement}

Subhash Pandharkar, Shruthi Nair, Ravindra Waykar, Ashish Waghmare and Dhirsing Naik are thankful to the Ministry of New and Renewable Energy (MNRE), Government of India for the financial support under National Renewable Energy Fellowship (NREF) program. Ajinkya Bhorde is thankful to Department of Science and Technology (DST), Government of India for INSPIRE Ph. D. fellowship. Rahul Aher is thankful to Savitribai Phule Pune University, Pune for the award of Bharatratna J. R. D. Tata Gunwant Sanshodhak Shishyavruti. Haribhau Borate is grateful to University Grant Commission (UGC), New Delhi for providing Teacher Fellowship under faculty development programme. One of the authors Sandesh Jadkar is thankful to University Grants Commission (UPE program), New Delhi and Indo-French Centre for the Promotion of Advanced Research-CEFIPRA, Department of Science and Technology, New Delhi for special financial support.

\section{References}

1. H. Ouyang, C. C. Striemer and P. M. Fauchet, Appl. Phys. Lett., 2006, 88, 163108.

2. H. Qiao, X. Chen, B. Wang, Z. Huang and X. Qi, J. Mater. Sci: Mater. Electron., 2019, 30, 3208-3213.

3. X. Xu, Y. Chen, W. Zhou, Y. Zhong, D. Guan and Z. Sha, Adv. Mater. Interfaces, 2018, 5, 1701693.

4. W. Yang, J. Chen, Y. Zhang, Y. Zhang, J. He and X. Fang, Adv. Funct. Mater., 2019, 29, 1808182.

5. R. K. Willardson, E. R. Weber, W. Paul and T. Suski, High Pressure Semiconductor Physics I. Vol. 54. Academic Press, (1998)

6. R. A. Street, Phys. Rev. Lett., 1982, 49, 1187.

7. M. V. Wolkin, J. Jorne, P. M. Fauchet, G. Allan and C. Delerue, Phys. Rev. Lett., 1999, 82, 197.

8. V. S. Waman, M. M. Kamble, S. S. Ghosh, A. Mayabadi, V. G. Sathe, H. M. Pathan, S. D. Shinde, K. P. Adhi and S. R. Jadkar, RSC Adv., 2012, 2, $9873-$ 9880.

9. B. Wu, T. Tsaia and D. Wuuab, Appl. Surf. Sci., 2015, 354, 216-220.

10. M. Mullenborn, J. Kuhmann, P. Scheel, Silicon-based sensor system, U.S. Patent 6, 522, 762 (2003)

11. G. Demin, N. Djuzhev, N. Filippov, P. Yu. G. Evsikov and N. Patyukov, J. Vac. Sci. Tech. B, 2019, 37, 022903.
12. S. Y. Reece, J. A. Hamel, K. Sung, T. D. Jarvi, A. J. Esswein, J. J. H. Pijpers and D. G. Nocera, Science, 2011, 334, 645.

13. L. Oakes, A. Westover, J. W. Mares, S. Chatterjee, W. R. Erwin, R. Bardhan, S. M. Weiss and C. L. Pint, Sci. Rep., 2013, 3, 3020.

14. R. J. Bozeat, S. Day, F. Hopper, F. P. Payne, S. W. Roberts and M. Asghari, In Silicon Photonics, pp. 269-294. Springer Berlin Heidelberg, (2004)

15. Y. Yang, J. Zhang, C. Fu, G. Liu, Y. Liu, X. Yao, X. Liu, Z. Chen and Z. Huang, Mater. Design, 2016, 107, 1-6.

16. M. Nayfeh, S. Rao, A. Smith, J. Therrien and M. H. Nayfeh, IEEE Photonics Technol. Lett., 2004, 16, 1927-1929.

17. R. Ayouchi, R. Schwarz, L. V. Melo, R. Ramalho, E. Alves, C. P. Marques, L. Santos and R. Almeida, O. Conde, Appl. Surf. Sci., 2009, 255, 5299-5302.

18. Y. K. Kim, Y. W. Park and S. H. Lee, U. S. Patent 6, 2002, 391, 803.

19. B. Jugdersuren, B. Kearney, X. Liu, R. Stroud, J. Culbertson, P. Desario, W. Nemeth and Q. Wang, Journal of Elec. Materi., 2019, 48, 5218-5225.

20. A. M. Funde, N. A. Bakr, D. K. Kamble, R. R. Hawaldar, D. P. Amalnerkar and S. R. Jadkar, Sol. Energy Mater. Sol. Cells, 2008, 92, 1217-1223.

21. S. Abdesselem, M. S. Aida, N. Attaf and A. Ouahab, Physica B: Condensed Matter, 2006, 373, 33-41.

22. M. Zheng, P. Gui, X. Wang, G. Zhang, J. Wan, H. Zhang, G. Fang, H. Wu, Q. Lin and C. Liu, Appl. Surf. Sci., 2019, 481, 437-442.

23. M. W. Knight, H. Sobhani, P. Nordlander and N. J. Halas, Photodetection with Active Optical Antennas Science, 2011, 332, 702-704.

24. R. Tripathi, O. Panwar, A. Kesarwani, I.1 Rawal, B. Singh, M. Dalaic, S. Chockalingam, RSC Adv., 2014, 4, 54388.

25. A. Kesarwani, O. Panwar, R. Tripathi, M. Dalai and S. Chockalingam, Mat. Sci. Semicon. Proc., 2015, 31, 1-9.

26. R. Tripathi, O. Panwar, I. Rawal, B. Singh and B. Yadav, J. Taiwan Inst. Chem. Eng., 2018, 86, 1-7.

27. A. S. Pawbake, R. G. Waykar, D. J. Late and S. R. Jadkar, ACS Appl. Mater. Interfaces, 2016, 8, 3359-3365,

28. R. Swanepoel, J. Phys. E Sci. Instrum., 1983, 16, 1214,

29. N. Budini, P. A. Rinaldi, J. A. Schmidt, R. D. Arce and R. H. Buitrago, Thin Solid Films, 2010, 518, 5349-5354.

30. G. B. Tong, Z. Aspanut, M. R. Muhamad and S. A. Rahman, Vacuum, 2012, 86, 1195-1202.

31. B. Cullity and S. Stock, Elements of X-ray Diffraction, $3^{\text {rd }}$ Edition, Princeton Hall (2001).

32. P. Gogoi, H. Jha and P. Agarwal, Thin Solid Films, 2011, 519, 4506-4510.

33. Z. Li, W. Li, Y. Jiang, H. Cai, Y. Gong and J. He, J. Raman Spectrosc., 2011, 42, 415-421.

34. D. Marquardt, J. Soc. Ind. Appl. Math., 1963, 11/2, 431-441.

35. D. Raha and D. Das, J. Phys. D: Appl. Phys., 2008, 41, 85303.

36. M. Acciarri, S. Binetti, M. Bollani, A. Comotti, L. Fumagalli, S. Pizzini and H. von Kanel, Sol. Energ. Mat. Sol. Cells, 2005, 87, 11-24.

37. J. Parramon, D. Gracin, M. Modereanu and A. Gajovic, Sol. Energ. Mat. Sol. Cells, 2009, 93, 1768-1772.

38. Y. He, C. Yin, G. Cheng, L. Wang, X. Lie and G. Y. Hu, J. Appl. Phys., 1994, 75, 797.

39. S. Chong, B. Goh, Z. Aspanut, M. Muhamad, C. Dee and S. Rahman, Appl. Surf. Sci., 2011, 257, 3320-3324.

40. J. Tauc and A. Menth, J. Non. Cryst. Solids., 1972, 8-10, 569-585.

41. N. Chopra, A. Mansingh and G. K. Chadha, J. Non. Cryst. Solids., 1990, 126, 194-201.

42. V. Kanneboina and P. Agarwal, J. Electr. Mater., 2019, 48, 2404-2410.

43. J. Gope, S. Kumar, S. Singh, C. Rauthan and P. Srivastava, Silicon, 2012, 4,127-135.

44. T. Zhai, L. Li, X. Wang, X. Fang, Y. Bando and D. Golberg, Adv. Funct. Mater., 2010, 20, 4233-4248.

45. F. H. L. Koppens, T. Mueller, P. Avouris, A. C. Ferrari, M. S. Vitiello and M. Polini, Nat. Nanotechnol., 2014, 9, 780-793.

46. Z. Alaie, S. M. Nejad and M. H. Yousefi, Mater. Sci. Semicond. Process, 2015, 29, 16-55

47. M. Buscema, J. O. Island, D. J. Groenendijk, S. I. Blanter, G. A. Steele, H. S. J. van der Zant and A. Castellanos-Gomez, Chem. Soc. Rev., 2015, 44, 3691-3718.

48. P. K. Kannan, D. J. Late, H. Morgan and C. S. Rout, Nanoscale, 2015, 7, 13293-13312. 
49. J. Qi, Y. Lan, A. Stieg, J. Chen, Y. Zhong, L. Li, C. Chen, Y. Zhang and K. Wang, Nat. Commun., 2015, 6, 7430.

50. C. Chen, H. Qiao, S. Lin, C. M. Luk, Y. Liu, Z. Xu, J. Song, Y. Xue, D. Li, J. Yuan and W. Yu, Sci. Rep., 2015, 5, 11830.

51. X. Wang, P. Wang, J. Wang, W. Hu, X. Zhou, N. Guo, H. Huang, S. Sun, H. Shen, T. Lin and M. Tang, Adv. Mater., 2015, 27, 6575-6581.

52. J. Cao, Z. Wang, X. Zhan, Q. Wang, M. Safdar, Y. Wang, J. He, Nanotechnol., 2014, 25, 105705.

53. Z. Hossain, S. L. Rumyantsev, K. M. Shahil, D. Teweldebrhan, M. Shur and
A. A. Balandin, ACS Nano, 2011, 5, 2657-2663.

54. W. Xiong, J. Chen, X. Wu and J. Zhum, J. Mater. Chem. C, 2015, 3, 1929 1934.

55. S. Liu, Z. Wei, Y. Cao, L. Gan, Z. Wang, W. Xu, X. Guo and D. Zhu, Chem. Sci., 2011, 2, 796-802.

56. A. R. Jha, Wiley and Sons, New York, 200, 245-359.

Publisher's Note Engineered Science Publisher remains neutral with regard to jurisdictional claims in published maps and institutional affiliations. 